\title{
Austria: Financial Sector Assessment Program Technical Note-Stress Testing and Short-Term Vulnerabilities
}

This technical note on Stress Testing and Short-Term Vulnerabilities for Austria was prepared by a staff team of the International Monetary Fund as background documentation for the periodic consultation with the member country. It is based on the information available at the time it was completed on June 13, 2008. The views expressed in this document are those of the staff team and do not necessarily reflect the views of the government of Austria or the Executive Board of the IMF.

The policy of publication of staff reports and other documents by the IMF allows for the deletion of market-sensitive information.

Copies of this report are available to the public from

International Monetary Fund $\bullet$ Publication Services

700 19th Street, N.W. • Washington, D.C. 20431

Telephone: (202) 623-7430 • Telefax: (202) 623-7201

E-mail: publications@imf.org • Internet: http://www.imf.org

Price: $\$ 18.00$ a copy

\section{International Monetary Fund Washington, D.C.}



Financial SECtor Assessment Program

\section{AUSTRIA}

TECHNICAL Note

STRESS TESTING AND SHORTTERM VULNERABILITIES

APRIL 2008

INTERNATIONAL MONETARY FUND

Monetary AND CAPITAL MARKETS DEPARTMENT 


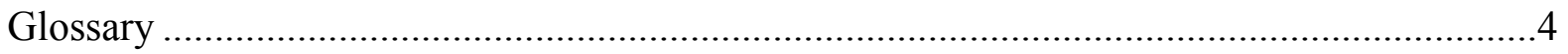

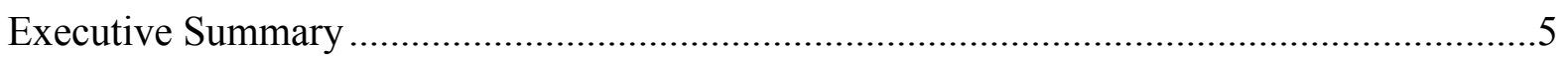

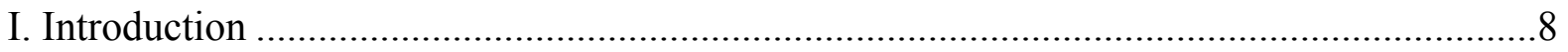

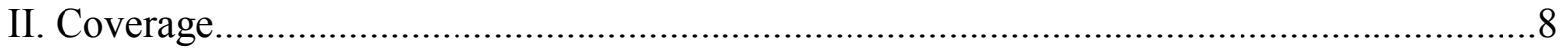

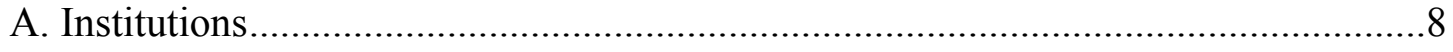

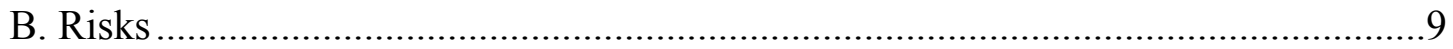

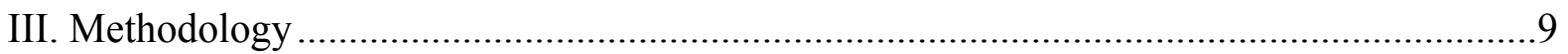

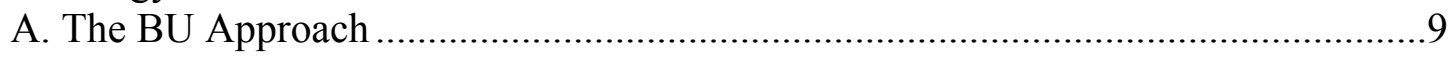

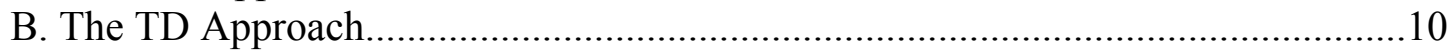

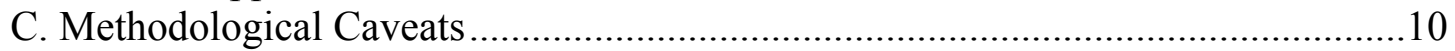

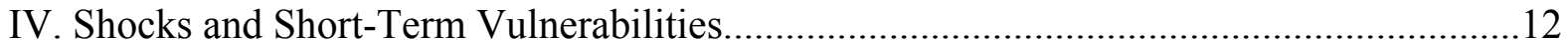

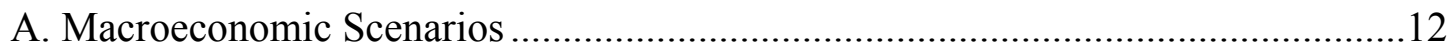

B. Market-Risk Shocks ................................................................................. 15

C. Indirect Credit Risk Induced by Foreign Exchange Rate Risk .............................16

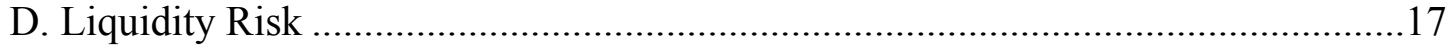

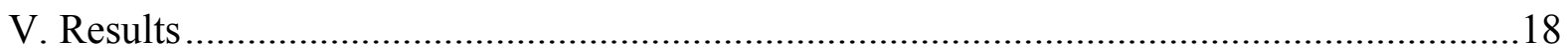

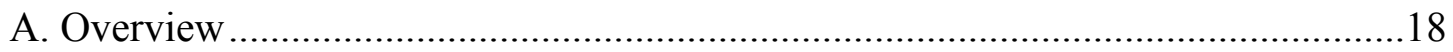

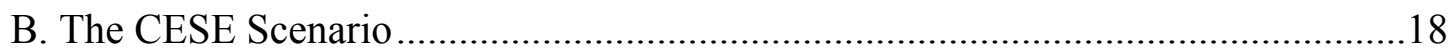

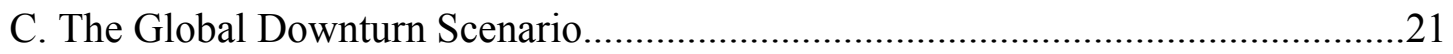

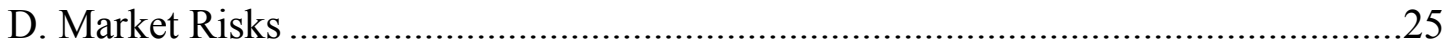

E. Indirect Credit Risk Induced by Foreign Exchange Rate Risk.............................26

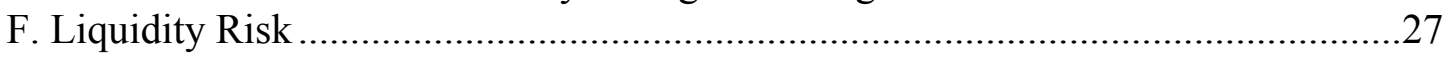

G. Qualitative Assessment of Risk Management ..............................................28

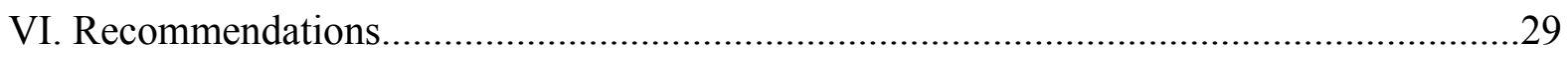

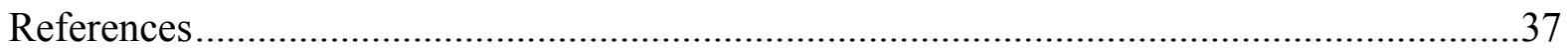

Tables

1. Real GDP and Profit Development Under the CESE Shock .......................................13

2. Real GDP, Profit, and Interest Rate Developments Under the

Global Downturn Shock ……………………………..................................................13

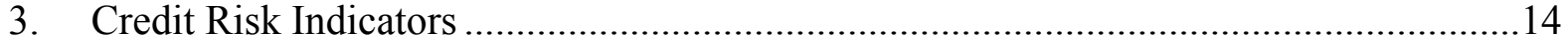

4. Market-Risk Scenarios ......................................................................................... 16

5. Average Impact of the CESE Scenario on the Six Largest Banks................................20

6. Average Domestic Impact of the Global Downturn Scenario on the

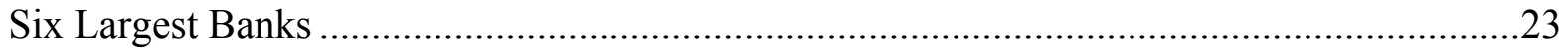

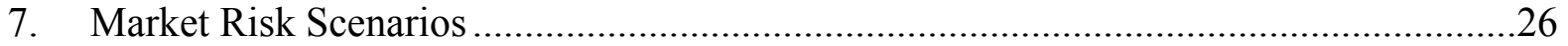


8. Liquidity Ratios Stress Test Results

Figures

1. Additional Credit Losses Under CESE Scenario

Appendixes

I. Modeling Credit-Risk Measures from Macro Factors .......................................................

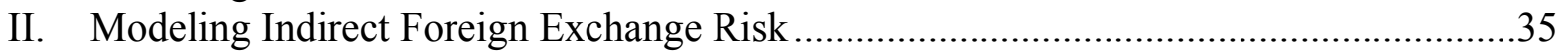

Appendix Table

9. Results of Regression of $\Delta^{l} L L P R$ on $\Delta^{l} G D P$ .36 


\section{GLOSSARY}

$\begin{array}{ll}\text { BA-Ca } & \text { Bank Austria Creditanstalt AG } \\ \text { BAWAG P.S.K. } & \text { Bank für Arbeit und Wirtschaft und Österreichische Postsparkasse AG } \\ \text { BIS } & \text { Bank for International Settlement } \\ \text { Bps } & \text { Basis points } \\ \text { BU } & \text { Bottom Up } \\ \text { CAR } & \text { Capital adequacy ratio } \\ \text { CESE } & \text { Central, Eastern, and Southeastern Europe } \\ \text { CHF } & \text { Swiss Franc } \\ \text { CIS } & \text { Commonwealth of Independent States } \\ \text { ECB } & \text { European Central Bank } \\ \text { Erste } & \text { Erste Bank der oesterreichischen Sparkassen AG } \\ \text { EU } & \text { European Union } \\ \text { EUR } & \text { Euro } \\ \text { FSAP } & \text { Financial Sector Assessment Program } \\ \text { FX } & \text { Foreign exchange } \\ \text { GDP } & \text { Gross domestic product } \\ \text { HAA } & \text { Hypo Alpe-Adria-Bank International AG } \\ \text { IRB } & \text { Internal Ratings-Based Approach } \\ \text { JPY } & \text { Japanese yen } \\ \text { LGD } & \text { Loss Given Default } \\ \text { LLPs } & \text { Loan Loss Provisions } \\ \text { NiGEM } & \text { The National Institute for Economic and Social Research's Global } \\ & \text { Economic Model. On the Internet at http://www.niesr.ac.uk } \\ \text { NMS } & \text { New Member States (of the European Union) } \\ \text { NMS-04 } & \text { New Member States that joined the EU in 2004 } \\ \text { NMS-07 } & \text { New Member States that joined the EU in 2007 } \\ \text { OeNB } & \text { Oesterreichische Nationalbank } \\ \text { OeVAG } & \text { Österreichische Volksbank AG } \\ \text { PD } & \text { Probability of Default } \\ \text { RoE } & \text { Return on Equity } \\ \text { RPVs } & \text { Repayment Vehicles } \\ \text { RZB } & \text { Raiffeisen Zentralbank Österreich AG } \\ \text { TD } & \text { Top Down } \\ \text { SEE } & \text { Southeastern Europe } \\ \text { SMEs } & \text { Small- and Medium-Sized Enterprises } \\ \text { SRM } & \text { OeNB's Systemic Risk Monitor (Boss et al., 2006) } \\ \text { USD } & \text { U.S. dollar } \\ & \end{array}$




\section{EXECUTIVE SUMMARY}

Stress tests show that the Austrian banking system exhibits considerable resilience against shocks. This resilience is supported by various factors. Financial institutions are generally well-managed and well-capitalized. Banks have a moderate attitude toward market risks, and generally follow an "originate and hold" strategy in lending, which results in relationship banking and yields incentives for careful monitoring of credit risk. In addition, many banks have a stable funding source in deposits, in part due to a tiered structure of the banking system, where small banks contribute to the liquidity of the apex institution of their sector. The banking sector as a whole exhibits ample liquidity.

The main sources of risk lie in the credit risk stemming from exposures to Central, Eastern, and Southeastern Europe (CESE) and the Commonwealth of Independent States (CIS), indirect credit risk from foreign currency lending, and credit risk from domestic lending. Several of the large Austrian banks have substantial exposure to CESE and the CIS, both via their foreign subsidiaries, as well as through direct lending to nondomestic clients. However, returns in CESE and the CIS are high, and, moreover, as is the case domestically in Austria, the banks mostly stick to traditional "originate and hold" banking. Foreign currency lending remains on a high level, both domestically (where it is declining as a percentage of total loans) and in some countries in CESE and the CIS. As the main exposure of most banks remains to Austria, domestic credit risk remains important. Market risks are generally modest, with the banks taking only small active positions.

The tested macroeconomic stress scenarios generated substantial strain on the banks, resulting in very low or in some cases even negative return on equity, but capital buffers generally remained intact. The macroeconomic scenarios applied in the stress tests center around severe shocks originating in CESE and a global downturn that causes a prolonged domestic recession. In both scenarios, the banks accrue substantial credit losses, thus severely affecting their return on equity. However, in most cases, the high profits of the banks would allow them to absorb most of the impact. Only in a few cases would the losses affect capital, and all of the large banks stayed well above the 8 percent minimum capital requirements under stress. Top-down analyses of supervisory data show, however, that a substantial number of smaller banks (albeit representing only a very small proportion of banking system assets) would be strained by severely adverse domestic macroeconomic developments. Many of these banks enjoy a form of guarantee from the sector of the banking system to which they belong, so actual default would not occur. In addition, no significant contagious defaults are predicted to ensue from the potential failure of these small banks.

Stress tests for indirect credit risk stemming from exchange rate movements confirm the resilience of the system, although the impact on the system as a whole and on some of the large banks is considerable. The stress tests involved simultaneous negative shocks to exchange rates and the performance of repayment vehicles connected with foreign exchange (FX) loans. The impact of the shock reflects primarily the large outstanding volume of FX loans. Although this volume is declining as a percentage of total loans in the domestic economy, and almost all of the domestic FX loan volume is now in Swiss francs 
rather than Japanese yen, the stress tests still show a substantial impact. The considerable impact can be explained in large part by the conservative modeling assumptions. A number of small banks, representing a very small part of banking assets, would experience severe strain, but, as before, most of them enjoy a form of guarantee from the sector of the banking system. Hence, no systemic impact would be expected. The stress tests for indirect credit risk were carried out off site by the authorities, and have not been compared with estimates from the banks themselves. Due to lack of data, these stress tests did not include FX loans in CESE and the CIS, which remain on the increase.

The Austrian banking systems as a whole exhibits ample liquidity. Many banks have a stable source of funding in deposits, in part due to the tiered structure of the banking system, where small banks contribute to the liquidity of the apex institution of their sector. The large banks all have in place liquidity management systems of various levels of sophistication. Liquidity stress tests, and the fact that recent credit market turmoil did not threaten liquidity at any of the large Austrian banks, suggest that banks follow a prudent approach toward liquidity. Nonetheless, going forward, the banks indicated that liquidity management is likely to gain further in prominence in the light of the prolonged nature of the market turmoil. However, given their funding structures, business models, and the setup of the banking groups of which they are part, none of the large banks see major strains over and above the generally higher market price for liquidity. This level of confidence seems justified, at least for the system as a whole.

In-depth discussions with the larger banks show that their modeling capacities vary. This partially reflects a different strategic focus of the banks (e.g., domestic retail and smalland medium-sized enterprises (SME) versus large corporates and/or large foreign exposures) but also reflects different stages in the preparation for internal ratings-based approach (IRB) approval. Banks focusing on large corporates generally employed more sophisticated credit risk models. The banks indicated that most risks were covered in the FSAP Update stress tests, and that the scenarios presented severe but plausible stress. However, one major bank remarked that their internal sensitivity stress tests sometimes show a more severe impact on credit risk indicators than those estimated under the scenarios used here.

Given the favorable macroeconomic developments over the last several years in Austria, CESE, and the CIS, credit risk indicators and loan loss provisions based on data from this period are likely to underestimate risks. This suggests that model risk might be present, and calls for conservative credit risk assumptions as a counterbalance. Several such assumptions underlie the results represented here, particularly in the top-down approach, where many worst-case assumptions were made, but necessarily rely to a large degree on judgment, which might turn out to be too optimistic.

\section{Based on these findings, the mission recommends that:}

- The authorities encourage and monitor the development of modeling capacity in the large banks. This could be achieved by more regular contacts between the authorities and banks on stress testing, e.g., by performing coordinated stress tests on 
a more regular basis. Banks should be encouraged to further develop capacity to model the link between the macroeconomic environment and their credit risk and profits, without having to rely on estimates from the Oesterreichische Nationalbank (OeNB). The authorities should pay specific attention to banks' treatment of model risk, in the current environment of high growth and the associated low perceived credit risk in CESE and the CIS, as well as domestically in Austria. In addition, some of the medium-sized banks could be encouraged to develop limited stress testing capabilities.

- The sophisticated off-site modeling capacity at the OeNB be used as a basis for an ongoing interaction with the large commercial banks on stress testing. The mission fully supports the continued emphasis on model development by the OeNB, and sees this as a key enabling skill for a continued dialogue with the banks on, in particular, credit risk modeling and the link between macroeconomic factors and credit risk.

- The authorities remain vigilant on the issue of indirect credit risk stemming from movements in exchange rates. Over the past few years, the authorities have focused on these risks through publications, public information campaigns, and the introduction of minimum standards for granting and managing foreign currency loans and loans with repayment vehicles (RPVs). The still-high level of domestic foreign currency loans, the large volume of FX loans abroad held by Austrian-owned subsidiaries, and the stress tests showing a substantial impact of exchange rate movements, point to the continued need for monitoring of these risks.

- The authorities remain alert to the concentrated exposure of the banks to the CESE and CIS region and intensify cross-border cooperation further. While the banks are generally well-diversified within this region, a general or contagious downturn in the region would significantly affect them. Moreover, a severe downturn in CESE might lead to funding problems for the Austrian banks, even though most funding is through deposits. Supervisors should continue to discuss these issues with the banks. In addition, this exposure and the associated risks argue for further intensification of cross-border supervisory cooperation. 


\section{INTRODUCTION ${ }^{1}$}

1. This note describes the methodology used for and the outcomes of stress tests carried out on the Austrian financial system. The tests were conducted as part of the Austria Financial Sector Assessment Program (FSAP) Update, to identify potential vulnerabilities in the financial system, be they on- or off-balance sheet. The shocks and macroeconomic scenarios applied in the tests are considered to be severe but plausible. Note that variations of the tests were carried out in order to assess the sensitivity of results to the assumptions; results are generally robust.

2. Two types of stress tests were carried out: macroeconomic scenario stress tests, and single factor stress tests. Both types of stress tests were undertaken in a decentralized, bottom-up (BU), as well as a centralized, or top-down (TD), way. The BU stress tests were done by the largest Austrian banks, using their internal risk models, and were coordinated by the OeNB. The TD stress tests were performed by the OeNB using available supervisory data. In collaboration with the FSAP team, the OeNB set the shocks and the macroeconomic scenario, provided guidance and oversaw the individual institutions' stress testing, and compiled the results of the stress tests. All macroeconomic stress tests, as well as the single factor market risk stress tests are based on end-June 2007 data.

3. The remainder of this technical note describes the coverage, the methodology, the shocks and the macroeconomic scenario, as well as the outcomes of the stress testing exercise and some forward-looking recommendations.

\section{Coverage}

\section{A. Institutions}

4. The stress tests centered on the six largest Austrian banks: Erste Bank der oesterreichischen Sparkassen AG (Erste), Bank Austria Creditanstalt (BA-Ca), Raiffeisen Zentralbank Oesterreich AG (RZB), Österreichische Volksbank AG (OeVAG), Bank für Arbeit und Wirtschaft und Österreichische Postsparkasse AG (BAWAG P.S.K.), and Hypo Alpe-Adria-Bank International AG (HAA). The six banking groups together have a 68 percent market share in terms of total assets in Austria, as well as major market shares in several countries in CESE, and the CIS. ${ }^{2}$ In addition, topdown stress tests were performed on supervisory data of all Austrian banks. Insurance companies were not included in the stress tests.

\footnotetext{
${ }^{1}$ The primary author of this document is Alexander Tieman (atieman@imf.org, +1-202-623-4434). The author and his colleagues would like to thank the Austrian authorities for exemplary cooperation and hospitality before, during, and after the mission.

2 The 68 percent domestic market share is based on consolidated data from mid-2007. Total bank assets in Austria were equivalent to about 300 percent of GDP in 2006, with 871 credit institutions active in Austria at end-2006. Their market shares in the CESE and CIS host markets vary between 1 and 53 percent.
} 
5. The stress tests cover all major portfolios of the institutions. Specifically, both the trading and the banking books were included in the exercise, as well as all on- and offbalance sheet items. ${ }^{3}$ The stress tests were done on a group level, i.e., including CESE and CIS subsidiaries, for the relevant macroeconomic scenario and, in the case of the BU approach, also for the market risk tests. ${ }^{4}$ Hence, the results can potentially illustrate geographic diversification benefits.

\section{B. Risks}

6. The stress testing exercise aims to include all major risks from macroeconomic sources faced by the banks. These consisted of two multi-factor macroeconomic scenario stress tests. The first scenario revolved around a large capital account adjustment and a concomitant recession in CESE, while the second scenario tested for resilience against a sharp global downturn, which resulted in a prolonged domestic recession. For both scenario tests, sensitivity analyses around the base stress scenarios were performed. In addition, for the global downturn scenario, the model allowed for an analysis of contagion through the interbank market. Moreover, all institutions performed single factor tests for market risks, in the form of shocks to interest rates, equity prices, exchange rates, and the implied volatility of options.

7. In addition to the scenario and single factor tests, assessments of short-term vulnerabilities were made. This was done by focusing on liquidity, through a qualitative as well as a limited quantitative analysis. Operational risk was not assessed.

\section{MeThOdOLOGY}

\section{A. The BU Approach}

8. The stress testing approach used in the BU exercise builds on the expertise of the individual banks and the OeNB to ensure consistency across institutions. The tests on credit and market risks were performed using the institution's own internal risk models. The BU stress tests were performed using end-June 2007 data as the basis for projections out to 2010. Banks were asked to report their results in millions of euros.

\section{While market risk models are well-established and hence exhibit a high degree} of consistency across institutions, credit risk models are less consistent across institutions. As banks routinely test market risks in their portfolios, such models are well developed. Although tests for credit risks are also performed routinely, financial institutions

\footnotetext{
${ }^{3}$ Under the TD approach, however, credit risk derivatives were not included due to the lack of data, while in the market risk stress tests derivatives were included with their respective delta weights.

${ }^{4}$ For the TD market risk stress tests, CESE and CIS subsidiaries could not be included in the calculations due to a lack of reporting data. However, these data will become available with the new reporting scheme, which will be put in place in 2008 .
} 
use a more diverse set of models for credit risk. These models may differ substantially in a number of ways, including in the linkages between macroeconomic variables and the credit portfolio, and hence the consistency across institutions might be in doubt under the scenario tests. To enhance consistency, the OeNB provided the banks with estimates for relative changes in the probabilities of default (PDs) and in loan loss provisions (LLPs) under the macroeconomic scenario. Banks used these changes in PDs and LLPs to estimate the impact on their respective portfolios. In addition, the OeNB provided the banks with a profile for profits before credit losses under the macroeconomic scenarios, which was estimated using bank profit data from the Asia crisis.

10. The short-term vulnerability assessments of liquidity focused on the six large banks. It consisted of a questionnaire, and a scenario, in which the liquidity of assets was shocked. The focus of the scenario was on effects on liquidity after 30, 60, and 90 days.

\section{B. The TD Approach}

11. The TD stress tests depend solely on the OeNB modeling of supervisory data. Similar to the BU approach, the TD approach consisted of tests of the market and credit portfolios of the banks. In addition, the TD approach allowed for an analysis of the entire Austrian banking system based on supervisory data. The TD stress tests were performed on end-June 2007 data. Results were obtained in millions of euros.

12. An analysis of contagion was done TD for the global downturn scenario, using an integrated model of the Austrian interbank market. The model combines standard risk management techniques with a network model of the Austrian interbank market (covering all maturities) and is based on supervisory filings. ${ }^{5}$

\section{Methodological Caveats}

\section{General caveats}

\section{Although the methodologies of both the BU and the TD approach are fairly} sophisticated, still, as always, caveats apply. For both types of stress tests, an important caveat is the lack of an interaction or feedback component between the different financial institutions in the stress tests. In other words, the setup of the exercise prevents full modeling of the externalities that vulnerabilities in parts of the financial system might levy on other parts of the system. ${ }^{6}$ However, some attempts are made to deal with this issue on a limited basis, like, e.g., performing sensitivity analyses around the base stress scenarios, adding a liquidity scenario, and assessing whether the domestic downturn scenario would result in any

\footnotetext{
5 This model relies on the OeNB's Systemic Risk Monitor (SRM, see Boss et. al 2006) and was adapted to account for the multi-periodicity of the macro scenario.

6 These issues generally apply to stress tests. In fact, the current academic debate has highlighted these issues as areas for further research. The OeNB is actively involved in such research.
} 
contagious defaults through the interbank market. The analysis of contagious defaults is based on a network model of the Austrian interbank market and represents an important step forward to deal with the interaction component between banks in a stressed environment.

14. Some caveats apply especially to the scenario tests. First, the starting position of the banking system, with a low level of defaults and high profit buffers, is unusually strong. Second, results would worsen when the scenarios exhibit more stress. Although the current CESE scenario is considered severe and plausible, a sharper adjustment of the current account deficit, possibly accompanied by large swings in CESE currencies versus the euro, could result in substantially larger losses. Third, the source and impact of stress may differ in a real downturn. Specifically, a severe downturn might yield contagion among the countries in CESE and the CIS, and consequently a larger spillover to Austria than seen historically. Fourth, the stress tests did not assess the feedback effects of the scenarios on the economic activity and asset prices in CESE and the CIS, which could result in an additional negative impact on Austria. Fifth, a severe downturn in CESE might lead to funding problems for the Austrian banks in the interbank market.

15. Another major caveat lies in the lack of modeling of reaction by the banks to the stress scenario. As the macroeconomic scenarios cover a period of three years, in reality, the banks will react to these different circumstances, which could improve (e.g., by raising capital) or worsen (through, e.g., "fire sales") the stress. However, such reactions are hard to model, and the current convention is to stress test under the assumption of fixed portfolios. To partially address this issue, the mission inquired about the possible reactions of the banks to the adverse macro scenarios.

\section{Specific caveats}

16. Some other caveats lie in the dispersion of models used and actual portfolios held by the different institutions. Different models might be geared to express certain types of vulnerabilities better than others. Differences in portfolios might exacerbate the impact of certain shocks beyond realism. As the shocks are calibrated to some average portfolio, they might seem extreme for certain institutions holding much lower-risk portfolios. This way, the impact shown in the tests can lose realism.

\section{A similar concern applies to the assumed uniform profit development before} credit-risk losses, which given the heterogeneity of the large Austrian banks' geographic diversification, is an oversimplification. In addition, the profit profile based on bank profit net of credit losses during the Asian crisis might not be an appropriate benchmark before stress, as the structure and pre-crisis profit developments of the affected Asian banks were different from those of the large Austrian banks, and many Asian banks exhibited severe underprovisioning. To partially deal with this issue, banks were given the opportunity to report alternate results based on their own forecasts of profits under the macroeconomic stress scenario.

18. Other caveats relate to data limitations, in particular in the TD stress tests. In the analysis, these limitations resulted in the need to make assumptions on loss given default 
(LGD), the incorporation of subsidiaries, and the ratings of individual corporates that are rated differently by different banks. In these cases, the more conservative assumptions were employed.

\section{SHOCKS AND SHORT-TERM VULNERABILITIES}

\section{A. Macroeconomic Scenarios}

19. The stress tests focused on two three-year macroeconomic scenarios. The first scenario centered around a regional shock in CESE and the CIS, while the second shock simulated a prolonged and severe global downturn. Both shocks were assumed to start in the third quarter of 2007, and the impact was simulated over a three-year horizon. Specifically, models are used to generate both baseline quarterly variables for 2007:Q3 to 2010:Q2, and for the same period under the stress scenarios. ${ }^{7}$

20. The CESE scenario assumes a confidence crisis in CESE, which results in a sharp decrease of about half of the current account deficit in the countries involved over the period of one year. As a consequence, risk premia increase, while a monetary policy reaction is disabled by assuming that the CESE countries continue to shadow the euro. The resulting real effects are severe, with the level of GDP up to 9 percent lower in 2008 in the two New Member States (NMS) that joined the EU in 2007 (Table 1), which would imply the slowest annual growth since the 1997-1998 crisis. These effects spill over to Austria via two main channels: the direct exposure of Austrian banks to the countries involved, via either local subsidiaries or cross-border lending from Austria, and the trade channel through Austrian exports to the region. Through the latter channel, exports decline up to 1.5 percent, resulting in Austrian GDP coming out around 1 percent lower than in the baseline scenario (excluding the indirect effect via the exposures of the banks to CESE and the CIS). In addition, Austrian bank profits before credit losses were assumed to decline by up to 17 percent from current levels. ${ }^{8}$

21. The global downturn scenario assumes a sharp downturn in the economies of Austria's main trading partners in Western Europe. In addition, it is assumed that the shock affects confidence in the form of a gradual rise in risk premia of $200 \mathrm{bps}$, and a gradual rise in the domestic household savings rate of 1.5 percentage points. The scenario focuses on

\footnotetext{
${ }^{7}$ Note that neither the baseline scenario nor the stress scenario should be seen as constituting official OeNB, IMF, or ECB projections in any way.

${ }^{8}$ The profit profile was estimated using bank profit data from the Asia crisis (see Section III). Given the heterogeneity of the large Austrian banks' geographic diversification, assuming a similar profit development for all of them is an oversimplification.
} 
Table 1. Austria: Real GDP and Profit Development Under the CESE Shock (Percentage deviations from baseline levels)

\begin{tabular}{lcccccccccccc}
\hline & $\mathbf{2 0 0 7}$ & $\mathbf{2 0 0 7}$ & $\mathbf{2 0 0 8}$ & $\mathbf{2 0 0 8}$ & $\mathbf{2 0 0 8}$ & $\mathbf{2 0 0 8}$ & $\mathbf{2 0 0 9}$ & $\mathbf{2 0 0 9}$ & $\mathbf{2 0 0 9}$ & $\mathbf{2 0 0 9}$ & $\mathbf{2 0 1 0}$ & $\mathbf{2 0 1 0}$ \\
& $\mathbf{Q 3}$ & $\mathbf{Q 4}$ & $\mathbf{Q 1}$ & $\mathbf{Q 2}$ & $\mathbf{Q 3}$ & $\mathbf{Q 4}$ & $\mathbf{Q 1}$ & $\mathbf{Q 2}$ & $\mathbf{Q 3}$ & $\mathbf{Q 4}$ & $\mathbf{Q 1}$ & $\mathbf{Q 2}$ \\
\hline GDP Austria & -0.4 & -0.4 & -0.6 & -0.8 & -0.9 & -1.0 & -1.1 & -1.1 & -1.1 & -1.1 & -1.1 & -1.0 \\
GDP NMS-04 & -1.7 & -2.7 & -3.5 & -4.0 & -4.4 & -4.2 & -3.9 & -3.5 & -3.2 & -2.9 & -2.7 & -2.5 \\
GDP NMS-07 & -5.9 & -7.3 & -8.1 & -8.5 & -8.7 & -7.4 & -6.1 & -4.9 & -3.8 & -2.8 & -2.0 & -1.3 \\
GDP SEE & -2.1 & -3.2 & -3.9 & -4.4 & -4.8 & -4.5 & -4.1 & -3.7 & -3.3 & -2.9 & -2.6 & -2.4 \\
GDP CIS & -0.1 & 0.0 & -0.1 & -0.2 & -0.3 & -0.4 & -0.4 & -0.5 & -0.6 & -0.6 & -0.6 & -0.6 \\
$\begin{array}{l}\text { Profit before } \\
\text { credit losses }\end{array}$ & -0.9 & -2.1 & -4.6 & -7.2 & -9.8 & -12.7 & -14.8 & -16.4 & -16.7 & -16.7 & -16.3 & -15.9 \\
\hline
\end{tabular}

Source: OeNB.

the domestic consequences of the shock, which are severe, with annual GDP growth declining to $2.8,-0.4$, and -0.1 percent for the years $2007-2009$, which is more prolonged than any other recession in Austria since the second world war. In addition, bank profits were assumed to decline up to 17 percent from current levels (Table 2). However, this scenario only takes the domestic effects into account. In other words, even though the cause of the recession is a global downturn, the indirect effects through the negative impact of the global downturn on CESE are not taken into account.

Table 2. Austria: Real GDP, Profit, and Interest Rate Developments Under the Global Downturn Shock

(Percentage deviations from baseline levels)

\begin{tabular}{|c|c|c|c|c|c|c|c|c|c|c|c|c|}
\hline & $\begin{array}{c}2007 \\
\text { Q3 }\end{array}$ & $\begin{array}{c}2007 \\
\text { Q4 }\end{array}$ & $\begin{array}{c}2008 \\
\text { Q1 }\end{array}$ & $\begin{array}{c}2008 \\
\text { Q2 }\end{array}$ & $\begin{array}{l}2008 \\
\text { Q3 }\end{array}$ & $\begin{array}{c}2008 \\
\text { Q4 }\end{array}$ & $\begin{array}{c}2009 \\
\text { Q1 }\end{array}$ & $\begin{array}{l}2009 \\
\text { Q2 }\end{array}$ & $\begin{array}{c}2009 \\
\text { Q3 }\end{array}$ & $\begin{array}{c}2009 \\
\text { Q4 }\end{array}$ & $\begin{array}{c}2010 \\
\text { Q1 }\end{array}$ & $\begin{array}{c}2010 \\
\text { Q2 }\end{array}$ \\
\hline GDP Austria & -0.6 & -1.5 & -2.4 & -3.2 & -4.1 & -4.7 & -5.2 & -5.8 & -6.1 & -6.2 & -6.2 & -6.1 \\
\hline $\begin{array}{l}\text { Profits before } \\
\text { credit losses } \\
\text { Short-term }\end{array}$ & -2.1 & -4.8 & -7.9 & -11.3 & -12.7 & -14.3 & -15.7 & -16.9 & -17.1 & -17.1 & -17.1 & -16.9 \\
\hline interest rate (bps) & 50 & 146 & 180 & 200 & 200 & 200 & 200 & 200 & 200 & 200 & 200 & 200 \\
\hline
\end{tabular}

22. The scenarios were calibrated using the OeNB's macroeconomic model of the Austrian economy, thus ensuring the consistency of projections for the various macroeconomic variables. For the CESE scenario, the inputs to the Austrian model were generated using the National Institute for Economic and Social Research's Global Economic Model (NiGEM) for the CESE and CIS countries, together with expert judgment for the variables not included in NiGEM. 
23. Since assessing the impact of the macroeconomic stress scenario on credit-risk exposures is not straightforward, the OeNB has assisted the financial institutions by providing estimated relative changes in domestic PDs and in LLPs for exposures to CESE and the CIS, consistent with the scenario. The changes in PDs were estimated based on a regression of default rates of Austrian corporates on macroeconomic variables, primarily the GDP development, unemployment rate, fixed capital investment, and the oil price, with some role for interest rates. ${ }^{9}$ The stress scenarios result in annual domestic default rates up to 28 percent higher for the CESE scenario and up to 71 percent higher in the global downturn scenario. However, the average base level of PDs is low. For the developments in CESE and the CIS, due to restrictions on data availability, a simpler approach was chosen, in which changes in LLPs were modeled directly as a function of GDP. In the scenario, LLPs are up to 145 percent higher than under the baseline for Romania and Bulgaria, with an increase of around 130 percent for the NMS 2004 and 116 percent for Southeastern European countries (Table 3).

Table 3. Austria: Credit Risk Indicators (Percentage deviation from baseline)

\begin{tabular}{lccc}
\hline & Year 1 & Year 2 & Year 3 \\
\hline & 11.2 & 18.0 & 27.6 \\
PDs Austria & 101.7 & 128.9 & 81.6 \\
LLPR NMS-04 & 134.6 & 145.2 & -29.1 \\
LLPR NMS-07 & 78.1 & 116.4 & 33.1 \\
LLPR SEE & 32.0 & 68.4 & 114.2 \\
LLPR CIS & \multicolumn{3}{c}{ Global Downturn Scenario } \\
\hline
\end{tabular}

Source: OeNB.

24. The banks were asked to report results in the form of credit losses in millions of euro. For the domestic side, this amounts to expected losses under the stressed PDs, while for the CESE countries, expected losses based on increases in LLPs were reported. Some banks with more advanced capabilities also reported estimates for unexpected credit losses. These results were subsequently related to profits (at the assumed reduced levels), as well as capital (i.e., regulatory own funds). Using a similar approach, results were calculated top down, using the OeNB off-site models.

\footnotetext{
${ }^{9}$ The PDs were estimated based on historically observed default frequencies from 1970 to mid 2007. Default frequencies were calculated on the basis of insolvencies and number of firms per quarter and industry sector as reported by the Austrian rating agency "Kreditschutzverband von 1870." For the second quarter 2007 the corresponding annualized PD for the overall Austrian economy was 2.7 percent.
} 
25. Top-down models were used also to calculate the sensitivity around the stress scenarios and analyze contagion. For the CESE scenario, alternative scenarios were run in which the credit-risk deterioration in some or all CESE and CIS countries is assumed to follow the more severe pattern estimated for Romania and Bulgaria, in combination with a shock to domestic confidence in the form of an increase in the domestic household savings rate of 2 percentage points. For the global downturn scenario, an analogous sensitivity analysis was performed in which the Austrian household savings rate is assumed to increase by an additional 2 percentage point (i.e., a total increase in the household savings rate of 3.5 percentage point compared to the baseline). Analyses of possible contagion in the Austrian banking system were performed for the global downturn scenario using an adapted version of the SRM that integrates a macroeconomic credit-risk model for individual banks with a network model of the Austrian interbank market. ${ }^{10}$

\section{B. Market-Risk Shocks}

26. Banks were asked to calculate the impact of a variety of major shocks on their portfolios, consisting of both the trading and banking books. In general, these shocks were calibrated in order to be severe but plausible, and in line with those employed in recent FSAPs for comparable countries. Tests were performed covering shocks to the (euro) interest rate curve, foreign and domestic equity indices, euro exchange rates, and implied volatilities. Credit spread risk was not assessed due to the very limited exposure of banks to this risk and the concomitant lack of tools to perform such assessments. The shocks are summarized in Table 4. In addition to these shocks, a substantial additional number of TD shocks were simulated to analyze the sensitivity around the shocks presented in Table 4 . These analyses were based on off-site supervisory data and included interest rate shifts and exchange rate shocks to the USD, JPY, CHF, and GBP. Estimated impacts (in terms of losses relative to capital) were negligible, and therefore they were not included in the BU exercise, in order to reduce the workload for the participating banks.

27. While the banks report the impact of the shocks in millions of euro, the results are presented here as percentage point decline in regulatory capital. As market-risk shocks are assumed to occur instantaneously, the impact should be assessed against the regulatory buffers held for such instances. This is a conservative way of presenting the market-risk results, as, in practice, regular banks profits, which are substantial for most banks, form a first buffer against losses. The impact of the market-risk shocks were also calculated top down, using available off-site supervisory data.

\footnotetext{
${ }^{10}$ All banks falling below a 4 percent capital adequacy ratio are assumed to default on their interbank liabilities, and the analysis shows if this would lead to any subsequent default of other banks. The 4 percent capital can hence be interpreted the costs associated with a default.
} 
Table 4. Austria: Market-Risk Scenarios

\begin{tabular}{|l|}
\hline Interest Rates \\
Parallel upward shift of euro yield curve by 200 bps \\
Parallel downward shift of euro yield curve by 200 bps \\
Steepening of euro yield curve through 200 bps increase of 10 -year rate \\
Equity Prices \\
Decrease in domestic equity prices by 35 percent \\
Decrease in nondomestic equity prices by 35 percent \\
Exchange Rates \\
Depreciation of euro by 15 percent \\
Appreciation of euro by 15 percent \\
Implied Volatility \\
Increase in implied volatility by 200 bps \\
Decrease in implied volatility by 100 bps
\end{tabular}

Source: OeNB.

\section{Indirect Credit Risk Induced by Foreign Exchange Rate Risk}

28. In addition to the standard market risk, a top-down analysis of indirect credit risk stemming from exchange rate movements was performed by the OeNB. The methodology is discussed in detail in Appendix II. An analysis of indirect credit risk stemming from FX movements is particularly relevant, as foreign currency lending in Austria stands at a high level, at 17.3 percent of total loans (some $€ 48.5$ billion), and around 29 percent of total loans to private households. These households are mostly unhedged, even though some households in the western Austria have income in Swiss franc. Much of the total foreign currency lending is currently in Swiss franc (CHF), with only 3 percent in Japanese yen (JPY) and approximately 6 percent in U.S. dollars (USD). ${ }^{11}$ Much of the private household foreign currency lending is for mortgages, and many of these loans (over 70 percent of households FX loans) have so-called RPVs associated with them. ${ }^{12}$ This introduces the additional risk of an underperformance or even loss of value of the RPV.

29. Shocks are assumed to occur with respect to exchange rates of the euro versus the Swiss franc (-10 percent) and the Japanese yen (-20 percent), while the RPVs are assumed to fall short of their expected performance by 15 percent. As many of the RPVs

\footnotetext{
${ }^{11}$ The single digit share of U.S. dollar FX loans did not change significantly over the course of the last couple of years and appears to be driven by naturally hedged exports of the Austrian industry.

${ }^{12}$ Frequently, the total amount of the loan remains outstanding for the duration of the contract (i.e., there is a bullet repayment), while at the same time the borrower saves funds in an RPV, which might for example be a non-term life insurance policy. The proceeds of the RPV are estimated to suffice for repayment at maturity.
} 
are in the form of life insurance policies, many of which have a guaranteed minimum return, a 15 percent shock can be considered severe. Results are presented in terms of percentage point of regulatory capital.

\section{Liquidity Risk}

30. Short-term vulnerabilities were assessed by focusing on liquidity. Liquidity stress tests were conducted for the six largest banks and consisted of both BU and TD components. The banks were asked qualitative questions on their compliance with BIS Sound Practices for Managing Liquidity in Banking Organizations (BIS, 2000). In addition, they were asked if they perform liquidity stress tests on a regular basis, and if so, to describe the typical scenarios involved.

31. The banks were also asked to run a specific liquidity scenario. The scenario assumed the spread between the secured and unsecured euro money market rates to increase by 80 bps. At the same time the pool of collateral accepted by parties in the secured market (with the exemption of government bonds) would shrink by 30 percent. Furthermore, 30 percent of currently eligible assets (again with the exemption of government bonds) would fall below the ECB quality threshold of single-A, and hence would no longer be eligible as collateral for loans from the central bank. This situation is assumed to last for 3 months, and the banks were asked to report the effects on their liquidity situation after 30 , 60 , and 90 days.

32. In addition, several top-down analyses on liquidity ratios for the largest six banks were performed. These ratios consisted of liquid assets to short-term liabilities, where short-term liabilities were defined as liabilities with a residual maturity of up to three month. Liquid assets consisted of cash reserves and debt instruments accepted for refinancing by the ECB, together with the portfolio of listed equities and bonds (liquidity ratio 1). In addition, two broader liquidity ratios were defined, in which respectively overnight or shortterm (up to three months remaining maturity) interbank and nonbank assets were added to liquid assets, where short-term nonbank assets are weighted by 0.5 (liquidity ratios 2 and 3 ).

33. The analyses centered around four single-factor shocks and a scenario that combined a severe disruption of the money and credit markets with an idiosyncratic shock for each of the banks. The single-factor shocks entailed 1) a decrease in the market value of liquid bonds of 25 percent; 2) a decrease in the market value of the equity portfolio of 35 percent; 3) a withdrawal of 40 percent of all short-term funding; and 4) a withdrawal of 50 percent of short-term deposits of nonbank customers. The scenario assumed a decrease in the market value of bonds and equities of 20 percent and 30 percent, respectively. In addition, each bank individually is assumed to face a bank-specific shock: nonbank customers were assumed to withdraw 10 percent of sight deposits, 20 percent of one-month deposits and 30 percent of three-month deposits. Assuming an additional effect on interbank lending among the banks, the total reduction in funding was assumed to amount to $-20,-30$, and -40 percent in the overnight, one-month and three-month segments, respectively. 


\section{Results}

\section{A. Overview}

34. The banks withstood the macroeconomic shocks well, but some weaknesses emerged. The credit losses that occur under the two scenarios were substantial, but, given high baseline profitability before credit losses, which was assumed to decline by up to 17 percent relative to the baseline, banks were generally able to absorb losses through these profits. Hence, returns on equity (RoEs) declined sharply but the effects on regulatory capital were minor. The effect on the group of six large banks varied substantially. In addition, outside of the group of large banks, a limited number of small banks fell below the 8 percent regulatory capital standards, which caused some losses for the system, but did not result in defaults due to contagion via interbank exposures.

35. Market risks were generally modest. The Austrian banks take only small active positions. Liquidity stress tests indicated that the large banks would not see major strains over and above the generally higher market price for liquidity.

\section{B. The CESE Scenario}

36. Credit-risk losses were substantial under the CESE scenario, but would not wipe out profits. Total losses for the largest six banks over a three year horizon amounted to some $€ 10$ billion in the TD results and $€ 6.3$ billion in the BU results. This compares to some $€ 41.4$ billion in total regulatory capital, and $€ 1.6$ billion in quarterly profits at mid-2007.

\section{Under this scenario, the credit risk was concentrated in the banks with large} exposures to the CESE and CIS region. Even among these banks, the impact was mixed, with two banks making losses in several quarters, while the others remained in the black. The accumulation of losses over time closely followed the macroeconomic development in the region (Figure 1): average credit losses reached a peak of $€ 189$ million in the TD estimation ( $€ 137$ million BU) in the third quarter of 2008 . Because of the heterogeneous nature of the banks, the standard deviation around this average was high over the entire scenario horizon. ${ }^{13}$

38. The impact is illustrated by a sharp decrease in RoE. The average TD estimate of RoE declined to 4 percent in the second year of the scenario, with three of the major banks exhibiting losses, one making a small profit and the other two banks maintaining RoEs of around 10 percent (Table 5). This indicates major strain in the sector, which in mid-2007 had an average RoE of 22 percent, while the large six banks exhibited RoEs between 9 and 28 percent. Bottom-up estimates of the RoE were somewhat higher, but still highlight considerable deviations from current profitability. Even though capital would not be affected in a substantial way because of profit buffers, banks would come under pressure to improve performance, either from inside their sector, or, in the case of foreign-owned or listed

13 The high standard deviation to a large extent reflects the relatively high credit losses in a single large bank. 
Figure 1. Austria: Additional Credit Losses Under CESE

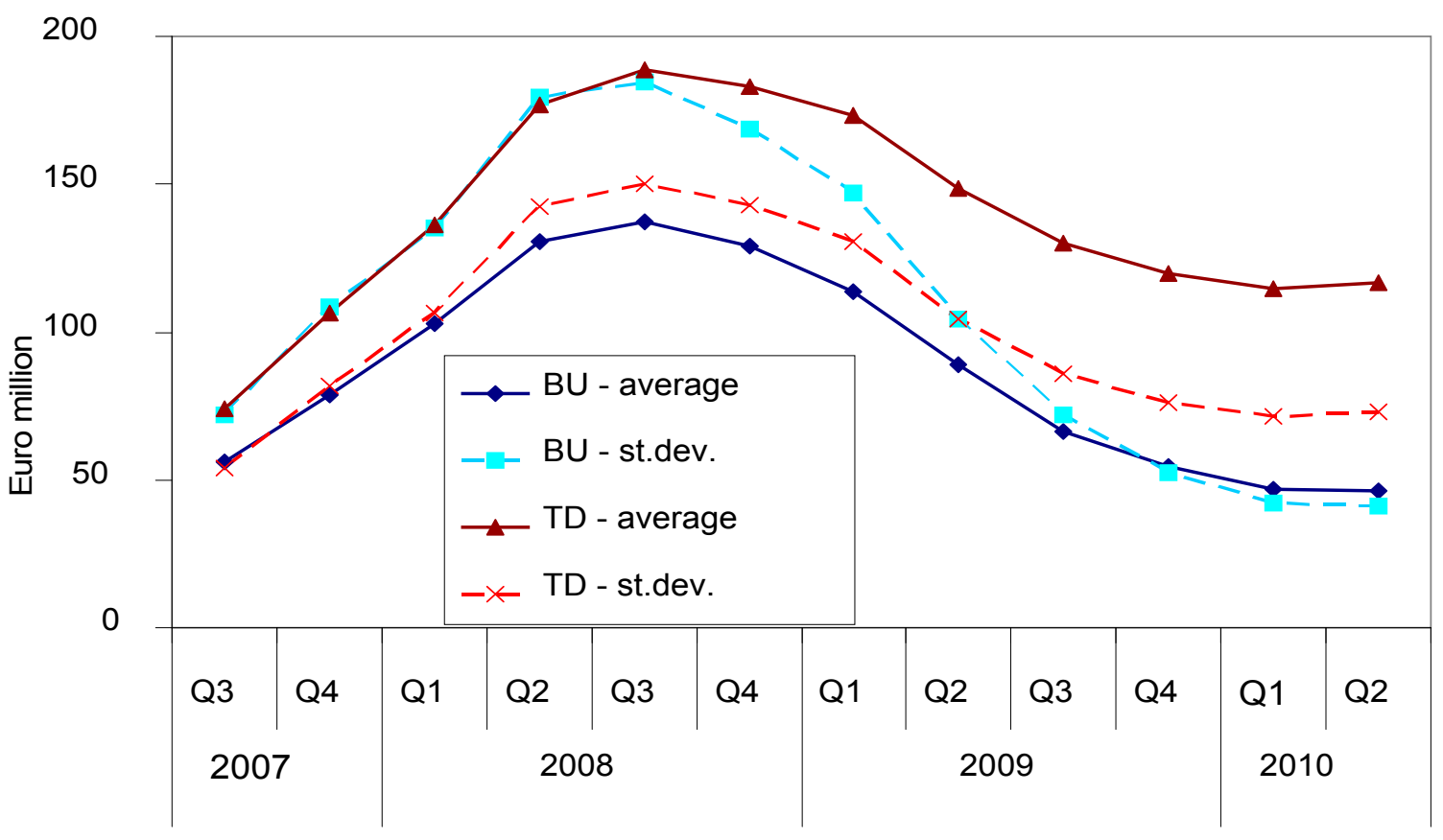

Sources: OeNB and banks' calculations.

entities, from their owners. Expressed in terms of profits, TD estimates suggested that the banks would lose about 18 months' profit (one year in the BU estimates), which amounts to some 2.8 percentage points when expressed in terms of regulatory (tier I + tier II) capital (i.e., when assuming zero profits).

39. The TD analysis generally yields a larger impact than the BU analysis. The difference can be explained by various factors. First, the TD analysis assumes a 100 percent LGD for the uncollateralized part of the credit portfolio, while the banks either use their internal estimates for LGD or use the standard 45 percent figure. Second, some of the banks have filed their loans to the public sector under the industry category "services," which results in a relatively low PD for this industry category (to which the changes in PDs provided by the OeNB were applied). The OeNB calculates expected losses based in this category based on higher PDs derived from historic default frequencies of corporates, i.e., not including loans to the public sector. A third difference, which biases the BU results upward, lies in the full inclusion of majority-owned subsidiaries in the banks' results, while the TD analysis assumes the losses accrue proportional to the percentage of ownership. Fourth, the portfolios covered in the TD and BU analyses are not entirely identical. While for the TD analysis for all banks the same reported data are used, the banks include and exclude different categories of assets in their BU estimations. Finally, the data included in the TD 


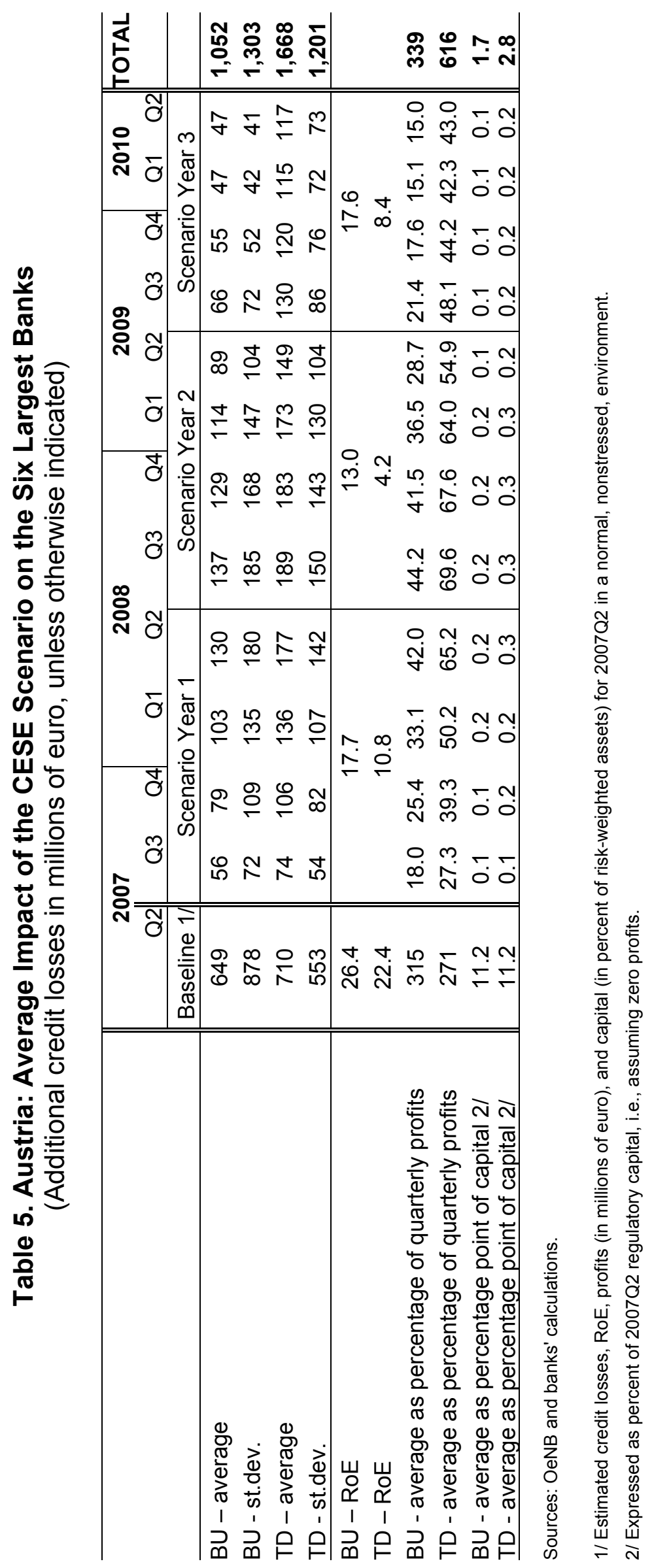


estimates of PDs is different, and might cover a longer period than the data included by the banks in their BU estimates. As the recent past has generally seen very favorable macroeconomic developments, estimation using data from this period will result in lower, and quite possibly overoptimistic, PDs. When replacing these generally more conservative TD assumptions with assumptions close to those used by the banks, the TD estimate of total losses comes down to $€ 4.5$ billion, against $€ 6.3$ billion in estimated additional losses in the $\mathrm{BU}$ analysis.

40. A top-down analysis for the entire Austrian banking system reveals that some of the smaller Austrian banks would be indirectly affected under the scenario. Lower domestic growth and increased domestic PDs would imply that approximately 1.1 percent of the banks would fall below the 8 percent capital ratio in year 3, while an additional 0.8 percent of banks would see their regulatory capital fall below 4 percent. However, the banks falling below the 8 percent capital limit represent a mere 0.3 percent of total banking assets. Moreover, most of these banks would benefit from support within their sub-sector of the banking sector, preventing actual defaults.

41. To assess the sensitivity of the CESE scenario to alternative assumptions, several alternative scenarios with more severe assumption were run on a top-down basis. These scenarios assumed credit-risk deteriorations in the entire CESE and CIS region to be aligned with the shock assumed for Romania and Bulgaria (i.e., the region experiencing the most severe shock). In addition, the household savings rate in Austria was shocked upward by 2 percentage points to simulate a confidence effect. Under the most severe of these alternative scenarios, which combines the two shocks sketched above, the impact remained modest, with credit losses in the large six banks amounting to $€ 11.1$ billion over three years (i.e., around $€ 1$ billion in additional losses compared to the baseline stress scenario). In this alternative scenario two of the major banks lose approximately 1 percentage point of regulatory capital, but all six banks remain comfortably above the 8 percent minimum capital requirement. Around 4 percent of all Austrian banks, representing 1.2 percent of banking assets, would fall below the 8 percent regulatory capital requirement, while some 1 percent of banks, representing 0.2 percent of assets would experience a capital decline to below 4 percent. As noted before, most of the problems in these banks would be resolved in their tier of the banking system, thus preventing actual defaults.

\section{The Global Downturn Scenario}

42. The global downturn scenario resulted in substantial credit losses, but would not wipe out profits. Total losses in the Austrian portfolios of the largest six banks over a three year horizon amounted to some $€ 4.9$ billion in the TD results and $€ 1.6$ billion in the BU results. This compares to some $€ 41.4$ billion in total regulatory capital, and $€ 1.6$ billion in quarterly profits at mid-2007. The losses are smaller than under the CESE scenario, as only the Austrian portfolios (excluding direct cross-border lending from Austria) were shocked.

43. Under this scenario, the credit risk was concentrated in the banks with largest domestic exposures. For most banks, expected losses rose by between 125 and 150 percent. 
However, as the reported baseline level of expected losses is low, at an average of $€ 305$ million, the total impact was only moderate. The pattern of losses points to higher quarterly losses as time progresses (Figure 2). This reflects the prolonged nature of the downturn and concomitant domestic recession. Specifically, the scenario does not provide for an upturn toward the end of the scenario horizon.

Figure 2. Austria: Additional Credit Losses under Global Downturn Scenario

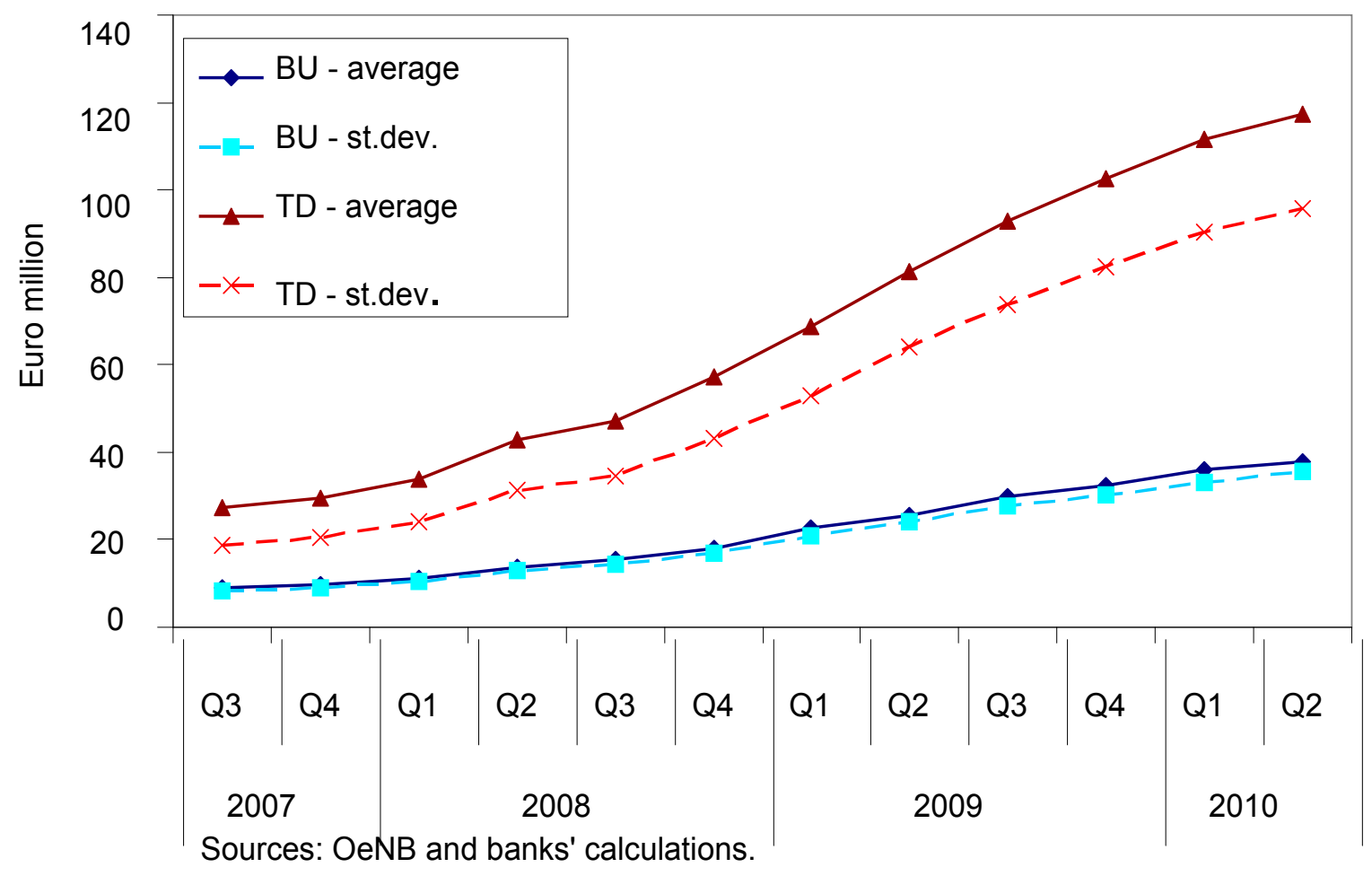

44. The impact is on RoE was considerable. Average TD-estimated RoE for the large six banks declined to 13 percent ( 21 percent BU) in year 2 and 9 percent (19 percent BU) in year 3 (Table 6). Half of the large six banks would see their RoE decline to below 10 percent in year 2, while in year 3 four out of the six banks would have an RoE below 5 percent. Meanwhile, one bank would exhibit a loss in year 3. This indicates major strain in the sector. Again, banks would come under pressure to improve performance, either from inside their sector, or, in the case of foreign-owned or listed entities, from their owners. Expressed in terms of profits, TD estimates suggest that the banks would lose about three quarters of a year's worth of profit (one quarter BU), which amounts to some 1.3 percentage points when expressed in terms of regulatory (tier I + tier II) capital (See Table 6). 


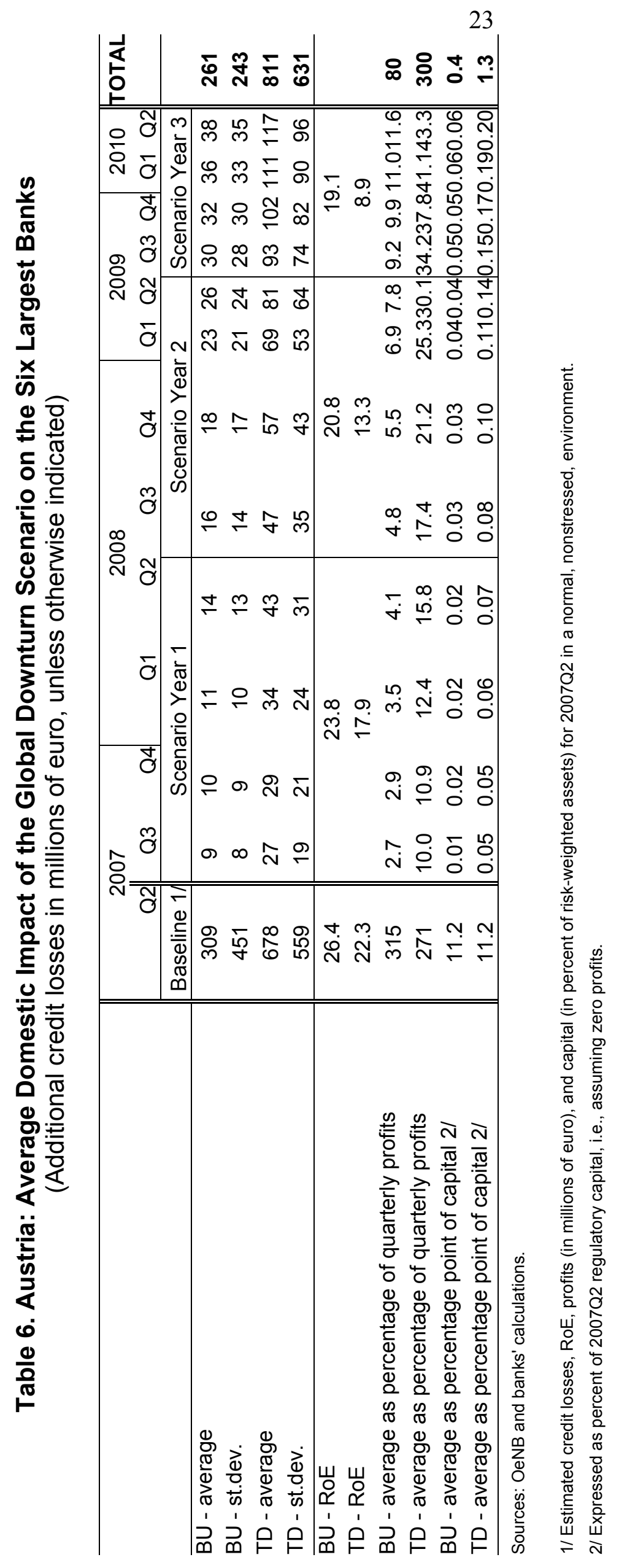


45. Under this scenario, the top-down analysis yields a much larger impact than the bottom-up analysis. As before, the difference can be explained by various factors, summed up in paragraph 42. A significant additional factor plays a role in the TD model used to simulate the shock on the domestic Austrian portfolio: for individual customers that have loans at more than one bank, and hence are rated by more than one bank, the TD model assumes the lowest (most risky) rating applies. The banks calculate with their own internal rating. As the larger banks are in general better able to assess credit risk, their ratings are often less conservative than those of smaller banks, thus biasing the TD estimates downward. The use of this most conservative rating from the Austrian credit registry for corporates with rating from multiple banks has a large impact on the results, because, in the case of this scenario, it affects the entire shocked portfolio. In addition, the results are affected by differing assumptions on LGDs. The issue with respect to the full or partial ownership of foreign subsidiaries does not affect the results, as foreign subsidiaries are not taken into account in this scenario. Differences in portfolios between the BU and TD models do exist, specifically because of the inclusion of already defaulted loans in the TD analysis (as these loans should be fully reflected in reported provisions as well), while at least one bank excluded those loans from the portfolio and treated the respective provisions separately. In addition, the possibility of overly optimistic credit-risk indicators in the BU models is present, when credit-risk indicators are estimated based on data over the last few years. If the appropriately conservative TD assumptions are replaced by assumptions on defaulted loans and PDs close to those used in the BU model (but keeping the higher LGDs), the TD estimate of total losses decreases to $€ 2.8$ billion, compared to $€ 1.6$ billion in the BU analysis.

\section{A top-down analysis for the entire Austrian banking system reveals that a significant number of smaller Austrian banks would be severely affected by the scenario, but the systemic impact would remain small. Lower domestic growth and} increased domestic PDs would imply that approximately 4.6 percent of the banks would fall below the 8 percent capital ratio in year 3 , while an additional 0.6 percent of banks would see their regulatory capital fall below 4 percent. In terms of assets, 1.4 percent of banks fall below the 8 percent capital requirement, while banks representing an additional 0.1 percent of assets fall below the 4 percent capital level. ${ }^{14}$ However, as before, most of the small banks coming under strain will benefit from support from their sub-sector of the Austrian banking system, thus preventing actual defaults. However, under the very conservative assumption that no such support takes place, problems in such a large number of small banks would result in a limited number of contagious defaults. When interbank exposures are taken into account and a bank that falls below 4 percent capital is assumed to default on its obligations (with 100 percent LGD), interbank contagion would cause the default of banks representing an additional 0.3 percent of system assets, for a total number of banks representing 0.4 percent of assets falling below 4 percent capital. Meanwhile, almost 5 percent of banks

\footnotetext{
14 Meanwhile, banks representing 91 percent of assets maintain a capital adequacy ratio above 10 percent.
} 
(representing 1.4 percent of system assets) would fall below the 8 percent capital requirement.

47. To assess the sensitivity of the global downturn scenario to alternative assumptions, an alternative scenario with more severe assumption was run TD. This scenario assumed a 2 percentage point higher Austrian household savings rate (on top of the 1.5 percent higher household savings rate in the baseline stress scenario) to simulate a severe confidence effect. Under this scenario, after contagious defaults are taken into account, the impact was moderately higher, with TD estimated credit losses in the large six banks amounting to $€ 5.7$ billion over three years (i.e., around $€ 0.8$ billion in additional losses compared to the baseline stress scenario). In this alternative scenario, one of the major banks loses approximately 0.6 percentage point of regulatory capital, but all six banks remain comfortably above the 8 percent minimum capital requirement. Around 6 percent of all Austrian banks, representing 2 percent of banking assets, would fall below the 8 percent regulatory capital requirement, while some 0.7 percent of banks, representing 0.4 percent of assets, would experience a capital decline to below 4 percent.

\section{Market Risks}

48. Market risk factors do not seem to be a major source of risk for the large Austrian banks. Interest rate risk dominates the other risks assessed, but remains limited. An instantaneous 200 bps increase across the entire euro yield curve would lead to losses corresponding to a decrease in capital of 0.2 percentage points on average, against an average capital ratio of 11.5 percent before the shock. The dispersion of the estimated effects across banks was large, but this result is driven by the fact that some banks stand to gain from an interest rate increase, i.e., the deviation is mostly upward. Vice versa, some banks stand to lose from a parallel downward shift in the euro yield curve. A steepening of the curve would lead to moderate losses.

49. Other market risk factors, including exposure to derivatives, are estimated to be minor compared to interest rate risk, with the exception of direct exchange rate risk. However, this result is largely driven by one bank that holds capital in its foreign subsidiaries in local currency and included its respective positions in the calculations, while this was not included in the TD analysis. ${ }^{15}$ This currency exposure is hence not the effect of active positioning, but rather the result of regulation, which the bank has chosen not to hedge. As the banks generally take only small active positions on equities and no position on volatility, the impact of shocks to these variables are estimated to be minor. Derivatives exposures seem limited, as indicated by the small impact of shocks to implied volatility.

50. Derivatives positions represent another source of the differences in results between the BU and TD analyses. While banks usually use data of individual positions or

\footnotetext{
${ }^{15}$ Note that, according to regulations, banks are allowed not to include equity positions in foreign currency in their respective net open positions that is reported to the OeNB and used for regulatory requirements.
} 
instruments in order to evaluate their market-risk exposures and to perform stress tests, the OeNB has to rely on reported data, which is by definition an aggregate over individual data. Though the reported aggregated data include derivative positions, these are usually added to the aggregate by using the respective delta weights. ${ }^{16}$ If a bank's portfolio contains complex structured products and/or combinations of "plain vanilla" derivative positions, the valuation of a position under specific scenarios could be rather different for the two approaches. In the extreme, the same scenario could show a loss (gain) using the aggregates, while the true result based on the individual positions would be the opposite, namely a gain (loss).

Table 7. Austria: Market Risk Scenarios (Change in capital adequacy ratio in percentage point)

\begin{tabular}{|c|c|c|c|}
\hline & & $\begin{array}{c}\text { Average impact } \\
\text { (weighted by assets) }\end{array}$ & $\begin{array}{c}\text { Dispersion } \\
\text { (unweighted standard } \\
\text { deviation) }\end{array}$ \\
\hline \multicolumn{4}{|l|}{ Interest Rates } \\
\hline Parallel upward shift of euro yield curve by $200 \mathrm{bps}$ & $\begin{array}{l}\text { BU } \\
\text { TD }\end{array}$ & $\begin{array}{l}-0.16 \\
-0.34\end{array}$ & $\begin{array}{l}0.20 \\
0.31\end{array}$ \\
\hline Parallel downward shift of euro yield curve by $200 \mathrm{bps}$ & $\begin{array}{l}\text { BU } \\
\text { TD }\end{array}$ & $\begin{array}{l}0.13 \\
0.39\end{array}$ & $\begin{array}{l}0.20 \\
0.36\end{array}$ \\
\hline Steepening of euro yield curve through 200 bps increase & $B U$ & -0.08 & 0.10 \\
\hline \multicolumn{4}{|l|}{ Equity Prices } \\
\hline Decrease in domestic equity prices by $35 \%$ & $\begin{array}{l}\text { BU } \\
\text { TD }\end{array}$ & $\begin{array}{l}-0.04 \\
-0.09\end{array}$ & $\begin{array}{l}0.05 \\
0.05\end{array}$ \\
\hline $\begin{array}{l}\text { Decrease in nondomestic equity prices by } 35 \% \\
\text { Exchange Rates }\end{array}$ & $\begin{array}{l}\text { BU } \\
\text { TD }\end{array}$ & $\begin{array}{l}-0.08 \\
-0.08\end{array}$ & $\begin{array}{l}0.15 \\
0.05\end{array}$ \\
\hline Depreciation of euro by $15 \%$ & $\begin{array}{l}\text { BU } \\
\text { TD }\end{array}$ & $\begin{array}{c}-0.14 \\
0.08\end{array}$ & $\begin{array}{l}0.33 \\
0.19\end{array}$ \\
\hline Appreciation of euro by $15 \%$ & $\begin{array}{l}\text { BU } \\
\text { TD }\end{array}$ & $\begin{array}{r}0.19 \\
-0.08\end{array}$ & $\begin{array}{l}0.31 \\
0.19\end{array}$ \\
\hline \multicolumn{4}{|l|}{ Implied Volatility } \\
\hline Increase of implied volatility by $200 \mathrm{bps}$ & BU & 0.00 & 0.01 \\
\hline Decrease of implied volatility by $100 \mathrm{bps}$ & BU & 0.00 & 0.00 \\
\hline
\end{tabular}

Sources: OeNB and banks' calculations.

\section{E. Indirect Credit Risk Induced by Foreign Exchange Rate Risk}

\section{Stress tests on indirect credit risk stemming from exchange rate movements} showed a considerable effect on some of the large banks and on the system as a whole.

\footnotetext{
${ }^{16}$ For option contracts, delta is a number that measures how much the theoretical value of an option will change if the underlying stock moves up or down $\$ 1.00$.
} 
The stress tests involved simultaneous negative shocks to exchange rates and the performance of repayment vehicles associated with many FX loans. The impact of the shocks reflected primarily the large outstanding volume of FX loans to mostly unhedged borrowers. In the scenario where the CHF/EUR rate is shocked downward by 10 percent and the repayment vehicle is assumed to perform 15 percent worse than baseline, the impact on LLPs was some 300 percent, which implies an impact of 1.4 percent of capital of the banking system. Roughly half of this impact was due to the FX movements, with the other half due to the underperformance of the RPV. For the large banks, the impact was lower, ranging from the equivalent of 0.1 percent of capital to 1.4 percent, with an asset-weighted average impact of 0.7 percent of capital. The impact of movements in the EUR/JPY exchange rate was minor, reflecting the current low volume of JPY loans.

52. The considerable impact can be explained in large part by the conservative modeling assumptions. For instance, the total impact from exchange rate movements was assumed to occur within a year, whereas many FX loans are for mortgages, with concomitant long durations. In addition, many of the RPVs are in the form of life insurance products, often with guaranteed minimum returns. Compared to some years ago, the risk has diminished considerably, due to the shift of the currency composition of domestic FX loans from JPY to the CHF, which has historically exhibited a lower volatility vis-à-vis the euro. In addition, the authorities have exerted considerable effort to limit these risks through publications, information campaigns, and the introduction of minimum standards for granting and managing foreign currency loans and loans with repayment vehicles. Still, the results indicated that FX loans should remain an area for continued vigilance both for the banks and for the supervisors and financial stability authority.

\section{F. Liquidity Risk}

\section{Compliance with the BIS principles for the Assessment of Liquidity}

Management in Banking Organizations is good. All of the six large banks reported that they comply with most principles, with the exceptions currently being addressed. The banks all perform simple liquidity stress tests on a regular basis.

\section{The banks all reported that under the liquidity stress scenario, their liquidity} position would remain comfortable. The reasons behind the limited impact were, first, the fact that most banks borrow interbank only on a secured basis, thus negating the effect of the increase of the spread between secured and unsecured loans. Second, most banks have such a large stock of eligible collateral that even a 30 percent reduction of that stock would still leave them with enough collateral for their liquidity needs.

\section{The top-down analysis showed substantial effects on liquidity ratios, but all of} the large banks would remain liquid. The single factor shocks reduced the short-term liquidity ratio 1 by some 30-35 percent, when 40 percent of short-term funding or 50 percent of nonbank deposits is assumed to be withdrawn (Table 8). The broader liquidity ratio 2 , which includes overnight funding, decreased by some 25-30 percent under these shocks, while the three-month liquidity ratio 3 decreased by only around 10 percent. The largest impact, however, was seen in the scenario shock, where the short-term liquidity ratio 
decreased by some 60 percent, or even 70 percent when overnight funding is included, while the three-month liquidity ratio decreased by 24 percent. Nevertheless, no bank would experience a liquidity shortage under any of the shocks.

Table 8. Austria: Liquidity Ratios Stress Test Results (In percent)

\begin{tabular}{lccc}
\hline & Liquidity Ratio 1 & Liquidity Ratio 2 & Liquidity Ratio 3 \\
\hline Mean & 45 & Unstressed system & 76 \\
Standard Deviation & 18 & 48 & 32 \\
\hline Mean & 38 & $23 \%$ reduction MV of liquid bonds \\
Standard Deviation & 16 & 41 & 69 \\
\hline Mean & & $35 \%$ reduction in MV of equities & 31 \\
Standard Deviation & 43 & 46 & 74 \\
\hline Mean & 17 & 25 & 34 \\
Standard Deviation & 30 & Withdrawal of $40 \%$ of ST funding & 73 \\
\hline Mean & 24 & 36 & 35 \\
Standard Deviation & 31 & 28 & 68 \\
\hline Mean & 20 & Withdrawal of 50\% of deposits & 45 \\
Standard Deviation & 19 & 32 & 58 \\
\hline Source: OeNB. & 21 & Scenario & 39
\end{tabular}

Source: OeNB.

\section{G. Qualitative Assessment of Risk Management}

56. The mission followed up on the quantitative results of the stress tests by conducting in depth discussion with the risk managers of the six large banks. These discussions, lasting some two hours each, focused on qualitative aspects of risk management. Specifically, the banks explained in detail how they used the input from the OeNB to run the stress tests. In addition, they were asked about the plausibility of the scenarios and assumptions behind the scenarios, as well as whether any specific additional risks could usefully be included in the stress testing exercise.

57. The quality of the discussions varied with modeling capacity and corporate focus of the banks. Specifically, the credit-risk modeling capacities differed across banks. Banks focusing on large corporates generally employed more sophisticated credit-risk models, and hence were able to discuss modeling in more detail. Some banks also indicated that, rather than working with PDs as inputs, they would have been interested in working with the macroeconomic data, which they could translate into risk indicators such as PDs 
themselves. ${ }^{17}$ However, as other banks lacked this capability, the OeNB chose to maintain consistency by providing all banks with a common set of relative changes to PDs and LLPs.

58. The banks indicated that most risks were covered and that the scenarios were realistic and presented severe stress. However, in some instances, they also remarked that their internal stress tests sometime show a more severe impact on PDs, particularly given the current low level of PDs and the fact that the impact on PDs was assumed to be relative rather than absolute. The choice of relative changes was based on the fact that absolute changes would present an artificial disadvantage for the banks with the safer portfolios (i.e., the lower PDs). As a minor aside, some banks mentioned that credit spread risks could usefully be covered under market risks, analogous to their internal market-risk stress tests.

59. The discussions indicated that some model risk might be present. The current environment of high growth, both in CESE and the CIS as well as domestically in Austria, has led to low credit-risk indicators during the last few years. As most models are based on data collected during this period, the estimates of credit-risk factors derived from these data might be somewhat optimistic. While the off-site model compensates for this with conservative assumptions on other variables, the degree to which the banks add a conservative margin to their estimates varies. This issue should remain a point of focus in further discussions between the authorities and the banks.

\section{RECOMMENDATIONS}

60. Based on the outcomes of the different stress testing exercises, credit risk emerges as the main risk factor. In addition, indirect credit risk stemming from FX loans and associated repayment vehicles is another risk that warrants continued attention. Market risk is generally moderate, with only small active position-taking.

\section{The authorities should monitor the development of modeling capacity in the} large banks closely. The level of sophistication differs across the largest Austrian banks. This partially reflects a different strategic focus (e.g., domestic retail and SME versus large corporates and/or large foreign exposures), but also reflects different stages in the preparation for IRB approval. In a number of the large banks there seems to be room for further development. One example would be to encourage the banks to further develop capacity to link the macroeconomic environment and their credit risk and profits, without having to rely on PD and profit estimates from the OeNB. Such development could be encouraged through more regular contacts with the authorities on stress testing.

62. The off-site modeling capacity at the OeNB is impressive, and could be used as a basis for an ongoing interaction with the commercial banks on stress testing. The

\footnotetext{
${ }^{17}$ As the OeNB did provide the macroeconomic data to the banks, the banks did have the possibility to model their own stress tests based on these data, and report these in addition to the standardized stress scenario based on PDs and LLPs. However, no bank chose to go down this route.
} 
sophistication of the off-site modeling reflects both a continued push for model development, as well as detailed data of good quality. The mission fully supports the continued emphasis on model development by the OeNB. In addition, the specific skills of the OeNB stress testing modelers enable a continued dialogue with the banks on, in particular, credit-risk modeling and the link between macroeconomic factors and credit risk. The authorities could consider structuring such a dialogue by, e.g., performing stress test with the banks on a more regular basis.

63. Going forward, two areas in off-site model development seem particularly suited for further investigation. First, in addition to the ongoing and past research, additional attention might be given to the modeling of PDs as a function of macroeconomic data. One option might be to assess the possibility of developing a structural model in which, e.g., interest rates play a more prominent role. ${ }^{18}$ Also, the authorities might want to investigate a modeling strategy focused on estimating absolute increases in PDs in addition to relative increases. As a separate exercise, it might be useful to try to reconcile further the off-site TD estimates of credit losses with the banks' BU estimates. As discussed above, several factors contribute to this, most prominently the conservative assumptions made in the off-site modeling. While the mission would argue for maintaining these conservative assumptions, a reconciliation exercise in which the assumptions are more in line with those of the banks, would serve to give additional confidence in the model. Indeed, the authorities performed such a reconciliation exercise during the mission.

\section{The importance of indirect credit risk stemming from shocks to FX rates} requires continued vigilance. This issue has been a major focus of the authorities over the last few years, as discussed above. Currently, domestic FX loans as a percentage of total loans are declining, but the high level of such loans, together with the stress tests showing a substantial impact, point to the continued need for monitoring these risks. The authorities, as well as the banks, are well aware of this issue and have indeed been monitoring it well. Indirect credit risk from FX loans in foreign subsidiaries currently is less well monitored, and effort might usefully be focused on improving the monitoring of these risks.

\section{Other risks that require vigilance follow from the concentrated exposure of the} Austrian banking systems to CESE and the CIS. While the banks are generally welldiversified within this region, a general or contagious downturn in the region would significantly affect the banks. Moreover, a severe downturn in CESE might lead to funding problems for the Austrian banks in the interbank market, even though most of their funding is through deposits. If the banks were to respond to such an eventuality by restricting credit to the affected countries, further negative macroeconomic effects might result. This exposure hence argues for continued vigilance by both the banks and the supervisor, as well as further intensification of cross-border supervisory cooperation.

\footnotetext{
${ }^{18}$ One could think of a structural model similar to that used to model indirect credit risk stemming from FX movements, where higher interest rates are reflected directly in lower disposable incomes, hence placing some households and corporates in higher risk brackets.
} 


\section{APPENDiX I: MODEling CREDIT-Risk MeAsures From MACRO FACTORS}

66. In order to assess the effect of a macroeconomic stress scenario on credit risk in the banking sector, some measure of credit risk has to be linked to the macroeconomic variables describing the scenario. For the Austrian credit portfolio this can be done by an econometric model linking the macro-variables to PDs of customers in different economic sectors. For the CESE countries, data availability prohibits the modeling of PDs or NPLs. Instead, LLPs, on which data are available, are modeled as a function of macroeconomic variables.

\section{A. Domestic Credit Risk}

67. The output of the OeNB's forecasting model is linked to the default probabilities of credits segmented into 10 economic sectors. The sectors are listed below, with the number of observed firms in each sector in June 2007 in parenthesis. Data of firms and defaulted firms were provided to the OeNB by Kreditschutzverband of 1870, the Association of Austrian Social Security Associations and Statistics Austria in quarterly frequency from 1969 to mid 2007. PDs are defined as the ratio of the number of default firms to the number of firms in each sector.

\section{Sectors:}

- Basic: Agriculture and basic Industries $(7,355)$

- Construction $(26,080)$

- Energy (840)

- Financial Services $(6,092)$

- Private (885)

- Production $(22,024)$

- Services $(77,162)$

- Tourism $(22,263)$

- $\quad$ Trading $(54,933)$

- Others

- Overall $(229,003)$

Due to the small number of firms in the sectors Energy, Private and Others a model referring to the overall Austrian economy is used for these sectors.

\section{General description}

68. The model linking credit risk in the banking sector to the macroeconomic environment is based on the methodology presented in Boss (2002), which links PDs of the overall Austrian economy to macroeconomic variables. This model is particularly suited for macroeconomic stress testing as it explicitly models credit risk in dependence on macroeconomic variables. However, in the following, sectoral PDs are linked to macroeconomic variables, which can be different for each sector. 
The average default probability $p_{s, t}$ in sector $s$ at time $t$ is modeled as a logistic function of a sector specific "macroeconomic index" which, in turn, depends on the current values of the macroeconomic variables under consideration:

$$
p_{s, t}=\frac{1}{1+e^{-y_{s, t}}},
$$

where $y_{s, t}$ denotes the macroeconomic index for sector $s$ at time $t$. Instead of estimating $p_{s, t}$ directly, in a first step "observed" values for the macroeconomic indices $y_{s, t}$ are calculated by taking the inverse of the logistic function of the historically observed PDs:

$$
y_{s, t}=-\ln \left(\frac{1}{p_{s, t}}-1\right) .
$$

As there is evidence that some of the macroeconomic indices $y_{s, t}$ are not stationary and in order to account for potential structural breaks in the time series, ordinary least square regression is used to explain changes in $y_{s, t}$ through changes in macroeconomic variables. In order to adjust for seasonal effects in the quarterly data logarithmic changes of moving averages over four periods of the macroeconomic variables are used as explanatory variables. PDs are also adjusted by using their moving average over four periods. Hence, for each sector $s$ the following regression model is estimated:

$$
\Delta y_{s, t}=\beta_{0, s}+\beta_{1, s} x_{1, s, t}+\beta_{2, s} x_{2, s, t}+\ldots+\beta_{K, s} x_{K, s, t}+\varepsilon_{s, t}
$$

where $\Delta y_{s, t}=y_{s, t}-y_{s, t-1}$ is the change of the macroeconomic index of sector $s$, calculated according to the respective equation above and $x_{1, s, t}, x_{2, s, t}, \ldots, x_{K, s, t}$ denote the macroeconomic variables for sector $s$ at time $t$ and $\beta_{0, s}, \beta_{1, s}, \beta_{2, s}, \ldots, \beta_{K, s}$ are the parameters to be estimated that determine the direction and extent of the impact the macroeconomic variables have on the index and ultimately, on the sector specific PD. The error term $\varepsilon_{s, t}$ is assumed to be an independent, normally distributed random variable $\varepsilon_{s t} \sim N\left(0, \sigma_{s}\right)$.

Having estimated the parameter vector $\hat{\beta}_{s}$, for each sector $s$ the model can be used to forecast sectoral PDs $\hat{p}_{s, t}$ as follows:

$$
\hat{p}_{s, t}=\frac{1}{1+e^{-\hat{y}_{s, t}}},
$$

where $\hat{y}_{s, t}=\hat{y}_{s, t-1}+\Delta \hat{y}_{s, t}$ and $\Delta \hat{y}_{s, t}$ is the forecasted change in the sector specific macroeconomic index calculated according to the estimated model given above where the actually observed value of the macroeconomic index $\hat{y}_{0}=y_{0}$ is used to calculate $\hat{p}_{1}$. 


\section{Model selection}

69. Using the model selection procedure for each sector as discussed in Boss (2002), we divided the potential macro-factors in seven groups. For each multivariate regression only one macro-variable from each group is integrated into the model. The following table provides the full list of macroeconomic variables that have been considered in the model selection process.

70. Starting with the set of 27 macroeconomic variables shown in the table, the model selection procedure was applied in order to find an optimal model for each sector. Optimal models have high explanatory power and reasonable overall statistical properties, and all estimates are statistically significant as well as economically meaningful. However, for five sectors ${ }^{19}$ no reasonable model could be found and hence a model based on the aggregated PD of the Austrian economy was applied. The remaining seven models contained two to four macro variables from the following set: GDP, industrial production, the unemployment rate, gross fixed capital equipment, the oil price, and the three-month real interest rate. Adjusted R squares of the models varied between 10 percent and 27 percent, which is rather low compared with other empirical evidence. This, however, can mainly be explained by the high variance in the quarterly time series, as similar models based on annual data typically show adjusted R squares above 50 percent.

\section{B. CESE Credit Risk}

\section{General description}

71. For the CESE region, reliable data on PDs are generally not available and, in the limited cases where at least some data could be gathered, the time series would certainly be too short to estimate sound econometric models linking the PDs to the economic environment. Hence, in case of CESE the use of PDs as a credit-risk measure is not feasible due to data limitations. Consequently, for CESE we apply alternative credit-risk measures, namely LLPs, which were already used in other FSAP missions as well as in various stress testing models of the OeNB. ${ }^{20}$ The main reason we based stress tests on LLPs instead of PDs or NPLs - the third commonly used credit-risk measure - is the availability of data. LLPs are the only data regarding credit risk that are currently reported from Austrian subsidiaries in CESE to the OeNB. Though there are certainly limitations to the use of LLPs as a credit risk measure (e.g., income smoothing), the same applies to NPLs (e.g., different regulations). Hence, we used LLPs for the sake of comparability.

72. Even on the basis of LLPs, the translation of the macroeconomic stress test scenario has to be done on the basis of expert judgment rather than econometric

\footnotetext{
19 These sectors were: basic industries, energy, financial services, private households, and others.

${ }^{20}$ For a recent example see Boss et al., 2007.
} 
modeling. Again, respective time series for most CESE countries are not long enough to capture several business cycles.

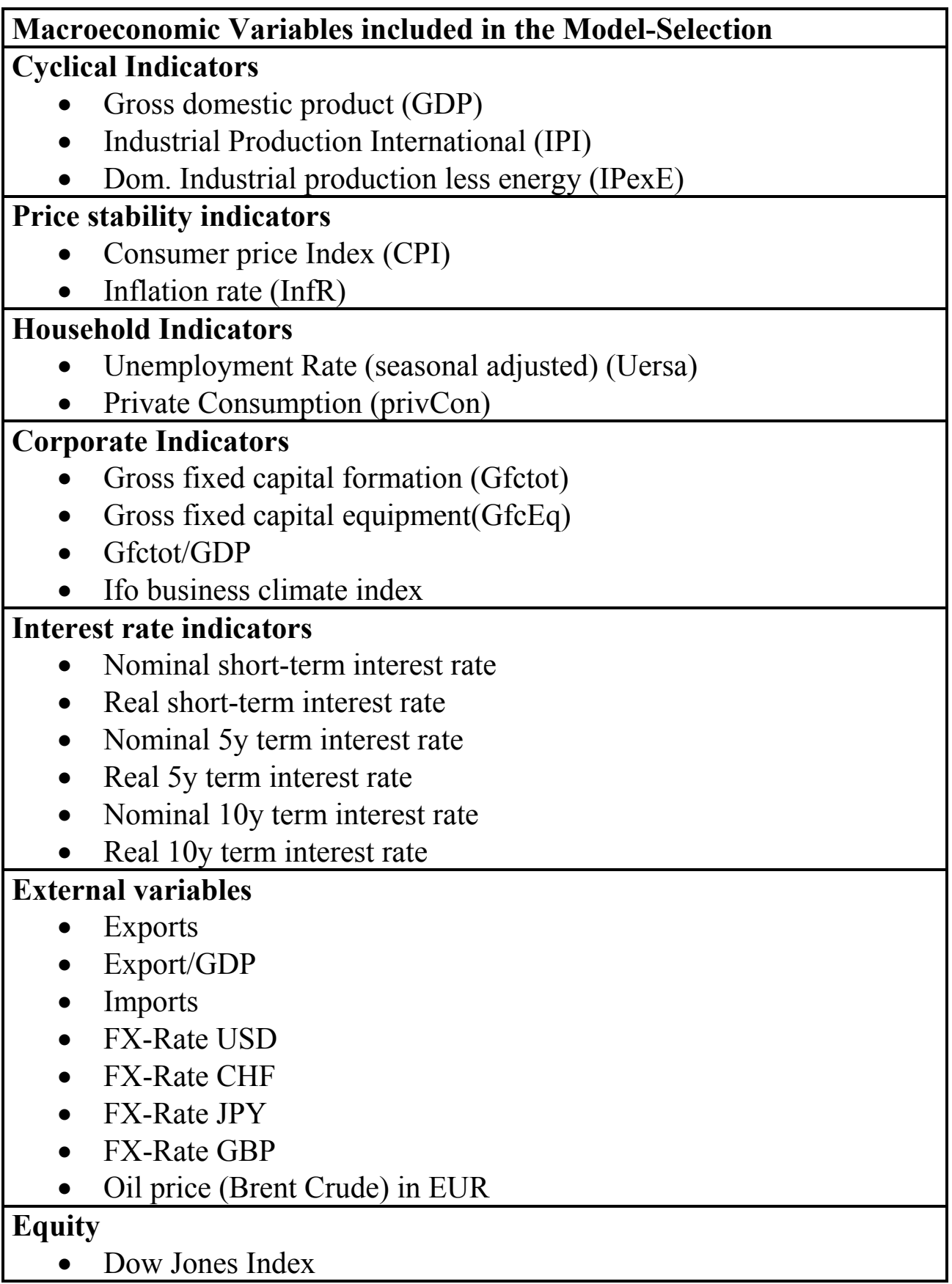




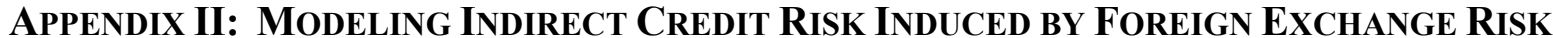

73. This appendix discusses the methodology used to estimate the indirect credit risk stemming from exchange rate movements. Specifically, the impacts of the changes in the FX rate and the performance of the repayment vehicle (RPV) are estimated on the basis of logarithmic changes of the loan loss provision ratio $\Delta^{l} L L P R$.

\section{A relative increase of the foreign exchange rate by $\Delta^{r} F X$ increases the} outstanding volume in Euro of a foreign currency loan by $D \cdot \Delta^{r} F X$, where $D$ denotes the outstanding volume of the foreign currency loan in euros. Under the assumption that the economic loss $D \cdot \Delta^{r} F X$ is incurred instantaneously, this can be interpreted as a decrease of the yearly income by $I \cdot \Delta^{r} I$, where $I$ denotes the yearly income and $\Delta^{r} I$ its relative change. The impact of the performance deviation of the RPV is integrated in a similar manner. Instead of estimating a loss in the repayment process an additional increase of the loan is assumed. The assumption that the economic loss resulting from the exchange rate movement and RPV performance is not amortized over the life time of the loan, but has to be fully covered in the current year, should be interpreted as a worst-case-boundary for the actual decrease of the yearly income.

These assumptions lead to the following equation

$$
-D \cdot\left(\Delta^{r} F X-\Delta^{r} R P V\right)=\Delta^{r} I \cdot I,
$$

which can be rewritten as

$$
\Delta^{r} I=-\frac{D}{I}\left(\Delta^{r} F X-\Delta^{r} R P V\right) .
$$

We further assume that a logarithmic change of the loan loss provision ratio $\Delta^{l} L L P R$ can be expressed in terms of the logarithmic change of the yearly income

$$
\Delta^{l} L L P R=\hat{\beta} \cdot \Delta^{l} I,
$$

where $\hat{\beta}$ is the estimated coefficient of the regression of $\Delta^{l} L L P R$ on $\Delta^{l} I{ }^{21}$

As we are interested in foreign currency loans regarding all economic sectors (i.e. household and corporate sector) we use real GDP-growth $\Delta^{l} G D P$ as a proxy for $\Delta^{l} I$. This gives an estimate of $\hat{\beta}=-2.5$, with the following statistics:

\footnotetext{
${ }^{21}$ Logarithmic changes are used, as, for this exercise, the regression was based on logarithmic data. A regression based on relative changes, however, would yield similar results, though the formula for the change of the loan loss provision ratio under stress (shown below) would have to be rewritten accordingly.
} 
Table 9. Results of Regression of $\Delta^{l} L L P R$ on $\Delta^{l} G D P$

Dependent Variable: $\triangle^{l} L L P R$

Method: Least Squares

Sample: 19842007

Included observations: 23 after adjusting endpoints

Newey-West HAC Standard Errors \& Covariance (lag truncation=2)

\begin{tabular}{lllll}
\hline \hline Variable & Coefficient & Std. Error & t-Statistic & Prob. \\
\hline Constant & 0.079155 & 0.040077 & 1.975075 & 0.0616 \\
$\Delta^{l} G D P$ & -2.528068 & 1.022124 & -2.473348 & 0.0220 \\
\hline R-squared & 0.147836 & Adjusted R-squared & 0.107257 \\
Log likelihood & 31.18585 & Durbin-Watson stat & 0.569031 \\
F-statistic & 3.643137 & Probability (F-statistic) & 0.070063 \\
\hline \hline
\end{tabular}

Source: OeNB

75. Finally we need an estimate of the leverage ratio $D / I$. As a proxy for $D$ we use the average size of a foreign currency loan, which is approximately $€ 130,000$, given a total volume of foreign currency lending to domestic customers of $€ 49$ billion from some 380,000 FX loans. As a proxy for $I$ we use the real GDP per unit labor force, as we are dealing with foreign currency loans regarding all households and the corporate sector, which was about $€ 60,400$ for 2007. This would suggest an estimate for $D / I$ in the rage between 2 and 2.5. We choose $D / I=2.5$.

Given the estimation described above, the relative change of the loan loss provision ratio under stress, which causes the decline of capital is calculated as follows:

$$
\begin{gathered}
\Delta^{r} L L P R=\left(\Delta^{r} I+1\right)^{\hat{\beta}}-1, \\
\Delta^{r} L L P R=\left[-\frac{D}{I}\left(\Delta^{r} F X-\Delta^{r} R P V\right)+1\right]^{\hat{\beta}}-1=\left[-2.5 \times\left(\Delta^{r} F X-\Delta^{r} R P V\right)+1\right]^{-2.5}-1 .
\end{gathered}
$$

This change in LLP is assumed to directly and fully impact capital, which leads to an outcome in terms of capital of

$$
\Delta \text { Capital }=V \cdot L L P R \cdot \Delta^{r} L L P R=V \cdot L L P R \cdot\left\{\left[-2.5 \times\left(\Delta^{r} F X-\Delta^{r} R P V\right)+1\right]^{-2.5}-1\right\},
$$

where $V$ denotes a bank's volume in loans in the respective currency. 


\section{REFERENCES}

BIS, 2000, Sound Practices for Managing Liquidity in Banking Organizations, Bank for International Settlements, Basel.

M. Boss, 2002, A Macroeconomic Credit Risk Model for Stress Testing the Austrian Credit Portfolio, OeNB, Financial Stability Report 4, Oesterreichische Nationalbank, Vienna.

M. Boss, G. Krenn, C. Puhr und M. Schwaiger, 2007, Stress Testing the Exposure of Austrian Banks in Central and Eastern Europe, Financial Stability Report 13, Oesterreichische Nationalbank, Vienna.

M. Boss, G. Krenn, C. Puhr und M. Summer, 2006, Systemic Risk Monitor: A Model for Systemic Risk Analysis and Stress Testing of Banking Systems. Financial Stability Report 11, Oesterreichische Nationalbank, Vienna. 